\title{
Parvovirus B19 infection in pregnancy
}

After its discovery in healthy blood donors in 1975, human parvovirus (B19) was shown to occur worldwide and to cause a spectrum of clinical manifestations including erythema infectiosum, aplastic crisis in patients with chronic haemolytic anaemia, chronic anaemia in immunodeficient patients, and acute arthropathy. ${ }^{1}$ The ability to produce a profound viraemia, a predilection for rapidly dividing cells, and the known fetotoxic properties of animal parvoviruses raised concern that B19 may be a hazard to the human fetus.

\section{Risk to the fetus}

Reports, in 1984, of intrauterine deaths associated with B19 infection ${ }^{2}{ }^{3}$ were followed by reassuring evidence of normal pregnancy outcome despite proved maternal and fetal infection. ${ }^{4}$ A transplacental infection rate of $33 \%$ has been estimated, ${ }^{5}$ although precise information on fetal risk and transplacental infection rates in the various stages of pregnancy has been difficult to obtain because, in contrast with rubella virus and cytomegalovirus, transplacentally acquired B19 rarely causes persistent infection throughout pregnancy. Consequently, measurement of B19 IgM in cord blood of surviving infants is a poor method of detecting intrauterine infection.

Maternal B19 infection in pregnancy, whether symptomatic or asymptomatic, is usually followed by successful outcome with delivery of a normal infant. However, fetal loss can occur at all stages of pregnancy ${ }^{5}$; in uncontrolled prospective studies the risk has been reported as $4 \cdot 1 \%$, $5 \%,{ }^{6} 7 \cdot 8 \%,{ }^{7}$ and $16 \% .^{5}$ Based on virological findings the Public Health Laboratory Service Working Party on Fifth Disease estimated the excess risk of fetal death due to B19 to be $9 \% .^{5}$ Preliminary data from a controlled study suggests a 2 to $3 \%$ increase in fetal deaths compared with controls. ${ }^{8}$

The greatest risk to the fetus occurs during the first 20 weeks of pregnancy ${ }^{7}$ and especially between weeks 10 and 20,5 which coincides with the major development of erythroid precursors. Risk assessment in the first trimester is complicated by the background spontaneous abortion rate, however, B19 is an uncommon cause of early spontaneous abortion. ${ }^{9}$ Fetal loss in the third trimester can occur. ${ }^{3}$

The interval between maternal illness and fetal death is usually three to five weeks, but may be as long as 11 weeks. ${ }^{5}$ Risk of fetal death due to B19 infection in pregnant women of unknown immunity who are exposed in the household or in the school has been estimated as $2 \cdot 3 \%$ and $1 \cdot 4 \%$ respectively. ${ }^{5}$ Approximately $50 \%$ of adults are immune.

\section{Fetal pathology}

Although malformations have occasionally been associated with B19 infection, ${ }^{10-12}$ there is no direct proof of causation by B19 and the rate of congenital anomalies is no higher than would be expected among infants in the general population. 45

Examination of tissues from B19 infected fetuses by in situ hybridisation combined with immunohistochemistry has demonstrated viral infection of erythropoietic cells in the bone marrow and in the microcirculation of many organs and of myocardial cells. ${ }^{13}$ Vasculitis may be present within placental villi. ${ }^{14}$

Hydrops fetalis is the commonest abnormality reported $^{14}$; B19 may account for $27 \%$ of cases of anatomically normal non-immune hydrops. ${ }^{13}$ B19 infects erythroid progenitor cells resulting in maturation arrest at the late normoblast stage; the fetus has a rapidly expanding red blood cell volume and a short red blood cell lifespan and is therefore particularly vulnerable. The resultant anaemia is thought to cause cardiac failure with subsequent ascites, effusions, and skin oedema. However, anaemia is not profound in all cases and red blood cell lysis, ${ }^{15}$ liver disease, ${ }^{1516}$ and myocarditis ${ }^{17}$ may be contributing factors. The cause of fetal death in the first trimester is uncertain but many tissues may be affected. ${ }^{11}$

There is increasing evidence that B19 infection may damage the fetal myocardium ${ }^{14}$ whether as a result of hypoxia or direct myocardial infection, however, cardiac abnormalities in surviving infants are unusual. ${ }^{18}$ An association between B19 infection and meconium peritonitis after perforation of dilated bowel proximal to jejunal or ileal obstruction has been reported. ${ }^{312} 1920$ Fetal B19 infection may be associated with neutropenia ${ }^{17}$ and thrombocytopenia ${ }^{1721}$ but the mechanism is not known. Long term follow up will be necessary to exclude late sequelae of intrauterine infection.

Passively acquired maternal antibody may not control infection ${ }^{22}$ but production of fetal IgM after approximately 18 weeks' gestation probably contributes to resolution of infection in surviving fetuses.

\section{Diagnosis of infection}

Current or recent maternal infection is usually diagnosed by the detection of B19 IgM in maternal serum, although it may not persist until delivery or miscarriage. Parallel testing of stored antenatal serum to detect rising B19 IgG concentrations may be necessary to confirm maternal infection. Confirmation of intrauterine infection in surviving infants usually requires the demonstration of B19 IgG at birth which persists at 1 year.

A variety of methods can be applied to postmortem material, including electron microscopy and B19 DNA detection by nucleic acid hybridisation or the polymerase chain reaction technique. ${ }^{8}$ These techniques have also been used for the prenatal diagnosis of intrauterine B19 infection using fetal ascitic fluid, ${ }^{17}$ fetal blood, 2122 or amniotic fluid. ${ }^{22}$

\section{Recognition of fetal disease}

Presenting features of prenatally diagnosed fetal B19 infections have included: a pre-eclampsia like syndrome, polyhydramnios, and abdominal pain. Ultrasonography may reveal fetal disease and an increased level of maternal serum $\alpha$ fetoprotein, probably representing excessive leakage across a damaged placenta, ${ }^{14}$ is often associated with an unfavourable outcome. ${ }^{219} 23$ Although it has been recommended that pregnant women with acute B19 infection should be monitored by assays for serum $\alpha$ fetoprotein, ${ }^{24}$ and by weekly ultrasound examination for 6 to 14 weeks $^{624}$ to detect fetal compromise at a potentially treatable stage, further studies are needed to define the role of these tests.

\section{Treatment}

B19 induced myocarditis has been treated by direct fetal digitalisation with prompt resolution of hydrops but subsequent fetal death. ${ }^{17}$ Intrauterine blood transfusion 
has been used to correct B19 induced anaemia ${ }^{7} 182125$ and has usually been followed by resolution of hydrops and successful outcome. However, in some cases improvement might have been spontaneous as there is increasing evidence that B19 associated hydrops can resolve without treatment and be followed by delivery of a normal infant. ${ }^{2022} 24$

Cordocentesis and intrauterine transfusion are not without hazard 2122 and there is concern that babies who would otherwise die could survive with congenitally acquired disease. It would be advisable for expertise in the treatment of B19 related hydrops to be developed in a limited number of centres so that risks can be minimised and the role of treatment can be defined. Ideally, rapid diagnostic facilities should be available at those centres in order that diagnosis, haematological assessment and treatment, if indicated, can be combined in one procedure.

\section{Patient management}

Although protocols have been proposed for the management of B19 exposure or infection in pregnancy, ${ }^{624}$ the very low risk to surviving infants and the uncertain role of therapeutic intervention suggest that management of individual patients should be through informed decisions made between patient and doctor.

Pregnant women who are in contact with B19 infection and are concerned about the possible consequences of infection should have serum tested for B19 IgM, B19 IgG, and also B19 DNA if that test is available. Any stored antenatal sample should also be tested. Those with evidence of prior immunity can be reassured. Susceptible women should be retested approximately four weeks after contact and on further occasions if exposure continues. There is no evidence that immunoglobulin preparations are of value in the prevention or treatment of B19 infection in pregnancy.

Although B19 infection can be an occupational risk for school personnel ${ }^{26}$ and health care staff, ${ }^{5}$ most women are unaware of the source of their infection and so it is normally inappropriate for susceptible, pregnant women to be excluded from work or transferred to low risk areas. ${ }^{5}$ Children and adults with typical features of disease are no longer infectious but patients with B19 induced transient asplastic crisis and immunodeficient patients with chronic B19 infection should be regarded as infectious by respiratory secretions ${ }^{1}$ and should not be cared for by non-immune pregnant health care workers.

Pregnant women who develop an illness compatible with B19 infection, most commonly rash and arthralgia, should be tested for both B19 and rubella infection. Testing stored antenatal serum aids interpretation of these results. Pregnant women with raised concentrations of $\alpha$ fetoprotein should also be tested for recent B19 infection.

If symptomatic or asymptomatic B19 infection is proved in a pregnant woman the implications should be discussed with her; infection is not an indication for termination. To increase our understanding of B19 infection in pregnancy it would be helpful if as many infected pregnant women as possible could be monitored for development of fetal disease. ${ }^{624}$ However, until the roles of monitoring and intrauterine transfusion have been clarified it would be reasonable to target patients who are particularly anxious for a successful pregnancy outcome. Whenever possible follow up should include examination of cord blood, serum at the age of 12 months, or fetal tissues.

A management protocol for prenatally diagnosed B19 associated hydrops fetalis has been proposed, ${ }^{24}$ but the indications for cordocentesis and intervention have not been defined.

C J HALL

Department of Microbiology,

The Horton General Hospital NHS Trust,

Oxford Road,

Banbury OX16 9AL

1 Centers for Disease Control. Risks associated with human parvovirus B19 infection. $M M W R$ 1989; 38: 81-8, 93-7.

2 Brown T, Anand A, Ritchie LD, Clewley JP, Reid TMS. Intrauterine parvovirus infection associated with hydrops fetalis. Lancet 1984; ii: 1033-4.

3 Knott PD, Welply GAC, Anderson MJ. Serologically proved intrauterine infection with parvovirus. BMF 1984; 289: 1660 .

4 Mortimer PP, Cohen BJ, Buckley MM, et al. Human parvovirus and the fetus. Lancet 1985; ii: 1012.

5 Public Health Laboratory Service Working Party on Fifth Disease. Prospective study of human parvovirus (B19) infection in pregnancy. Prospective study of human

6 Rodis JF, Quinn DL, Gary GW, et al. Management and outcomes of pregnancies complicated by human B19 parvovirus infection: a prospective study. Am F Obstet Gynecol 1990; 163: 1168-71.

7 Enders G, Biber M. Parvovirus B19 infections in pregnancy. Behring Inst Mitt 1990; Aug (85): 74-8.

8 Torok TJ. Human parvovirus B19 infections in pregnancy. Pediatr Infect Dis F 1990; 9: 772-6.

9 Rogers BB, Singer DB, Mak SK, Gary GW, Fikrig MK, McMillan PN. Detection of human parvorvirus B19 in early spontaneous abortuses using serology, histology, electron microscopy; in situ hybridization and the polymerase chain reaction. Obstet Gynecol 1993; 81: 402-8.

10 Weiland HT, Vermey-Keers Chr, Salimans MMM, Fleuren GJ, Verwey RA. Parvovirus B19 associated with fetal abnormality. Lancet 1987; i: $682-3$.

11 Van Elsacker-Niele AMW, Salimans MMM, Weiland HT, Vermey-Keers $\mathrm{Chr}$, Anderson MJ, Versteeg J. Fetal pathology in human parvovirus B19 infection. Br f Obstet Gynaecol 1989; 96: 768-75.

12 Bernard JD, Berrebi A, Sarramon MF, et al. Infection materno-foetale a parvovirus humain B19. f Gynecol Obstet Biol Reprod (Paris) 1991; 20: 855-9.

13 Morey AL, Porter HJ, Keeling JW, Fleming KA. Non-isotopic in situ hybridisation and immunophenotyping of infected cells in the investigation of human fetal parvovirus infection. F Clin Pathol 1992; 45: investigat $673-8$.

14 Morey AL, Keeling JW, Porter HJ, Fleming KA. Clinical and histopathological features of parvovirus B19 infection in the human fetus. Br f Obstet Gynaecol 1992; 99: 566-74.

15 Anand A, Gray ES, Brown T, Clewley JP, Cohen BJ. Human parvovirus infection in pregnancy and hydrops fetalis. $N$ Engl $\mathcal{f}$ Med 1987; 316: 183-6.

16 Metzman R, Anand A, DeGiulio PA, Knisely AS. Hepatic disease associated with intrauterine parvovirus $B 19$ infection in a newborn premature infant. F Pediatr Gastroenterol Nutr 1989; 9: 112-4.

17 Naides SJ, Weiner CP. Antenatal diagnosis and palliative treatment of non-immune hydrops fetalis secondary to fetal parvovirus B19 infection. Prenat Diagn 1989; 9: 105-14.

18 Schwarz TF, Roggendorf M, Hottentrager B, et al. Human parvovirus B19 infection in pregnancy. Lancet 1988; ii: $566-7$.

19 Bloom MC, Rolland M, Bernard JD, Fournie A, Berrebi A, Regnier C. Infection materno-foetale a parvovirus associee a une peritone meconiale antenatale. Arch Fr Pediatr 1990; 47: 437-9.

20 Zerbini M, Musiani M, Gentilomi G, et al. Symptomatic parvovirus B19 infection of one fetus in a twin pregnancy. Clin Infect Dis 1993; 17: 262-3.

21 Peters MT, Nicolaides KH. Cordocentesis for the diagnosis and treatment of human fetal parvovirus infection. Obstet Gynecol 1990; 75: 501-4.

22 Torok TJ, Wang Q-Y, Gary GW, Yang C-F, Finch TM, Anderson LJ. Prenatal diagnosis of intrauterine infection with parvovirus $B 19$ by Prenatal diagnosis of intrauterine infection with parvovirus B19 by the polym

23 Carrington D, Whittle MJ, Gibson AAM, et al. Maternal serum $\alpha$-fetoprotein - a marker of fetal aplastic crisis during intrauterine human parvovirus infection. Lancet 1987; i: 433-5.

24 Sheikh AU, Ernest JM, O'Shea M. Long-term outcome in fetal hydrops from parvovirus B19 infection. Am f Obstet Gynecol 1992; 167: 337-41.

25 Sahakian V, Weiner CP, Naides SJ, Williamson RA, Scharosch LL. Intrauterine transfusion treatment of non immune hydrops fetalis secondary to human parvovirus B19 infection. Am $\mathcal{F}$ Obstet Gynecol 1991; 164: $1090-1$.

26 Gillespie SM, Carter ML, Asch S, et al. Occupational risk of human parvovirus B19 infection for school and day-care personnel during an outparvovirus B19 infection for school and day-care personnel 